\title{
Psychological Healing Change of Workers Following After the Experiencing Indoor Garden Installation
}

\author{
Hye Sook Jang, Gyung Mee Gim, Kwang Jin Kim, and Hyun Hwan Jung* \\ National Institute of Horticultural \& Herbal Science, RDA, Wanju-gun 55365, South Korea
}

\begin{abstract}
This study was taken place to find out the psychological change with comparing before and after the experience of installation of indoor garden with 55 of subjects out of 62 subjects. More than $50 \%$ of subject answered that the garden management would be difficult before they experience the installation but the pressure was decreased while the interest of plants and landscape increased, however, the burden of management decreased and the interest in the kinds of plants and landscape design tended to increase after the experience of the installation. The psychological effect of indoor garden of workers was significantly increased with the question of "Indoor garden improves effect of air cleaning." after the experience of installation and the loyalty was statistically increased with the question of "Intend to invest more fund to purchase indoor plant" $(p<.05)$. As a result of the comparison of two psychological indicators, the recovery index of the state according to experience of indoor gardening was significantly higher after experiencing the indoor garden than before the indoor gardening experience. As the result of sensibility evaluation of pleasant, natural and calm with semantic differential method, workers feel more of them with the indoor garden. In addition, the loyalty was statistically significantly higher in the question "I would be willing to invest more in plant purchase" after experiencing the composition indoor garden $(p<.05)$. This result is similar to the result that the resident's recovery index, pleasantness, calm feeling, and emotional index are higher the indoor garden in public resting area with indoor garden than without indoor garden. With this study, the perception of indoor garden changed as a result of the worker's experience of indoor gardening in the workplace and the view of the indoor garden created by the workers. As the psychological healing effect of indoor garden increased, increase in the cost investment for the emotional health promotion of the workers is expected to have a positive effect on the increase of the indoor garden.
\end{abstract}

Keywords: foliage plant, interest of plants and landscape, plants and landscape design pleasant

\section{Introduction}

As the lives of modern people are getting more and more distant from the greenery due to urbanization and overpopulation, the stress of workers who live and work most of the day in the building is increasing further and accordingly their mental fatigue is getting bigger (Yoo , 2013). When we consider human history to be about five million years, most of the time we have adapted to the natural environment during evolution, so we feel the sense of security in the natural environment, and this natural landscape has the effect of relieving mental stress (Miyazaki et al., 2011; Ulrich et al., 1991). The urban

This study was conducted in the support project (PJ011376042017) of post-doctoral course of the National Institute of Horticultural \& Herbal Science, RDA in 2017.

Received: July 21, 2017, Revised: August 3, 2017, Accepted: August 9, 2017

*Comesponding author: baramdosa@korea.kr 
environment of modern times causes various stresses to humans, and these excessive stresses are reported to deteriorate diseases such as angina, diabetes, hypertension, etc. and weaken the immune function, harming health (Astin et al., 2003; Choi et al., 2011).

Recently, the number of workers who are suffering from stress is on the rise and the working hours of Korean office worker who spend most of time in indoor office working hours is longer than other countries. According to the average working hours per worker in member countries of the Organization for Economic Cooperation and Development (OECD) in 2015, Korea has 2273 hours per year, 507 hours longer than OECD average (1766 hours) and 902 hours longer than Germany, topping among OECD member countries. Likewise the average number of working hours is the highest while the survey of National Statistical Office (NSO) in 2014 found that job satisfaction was low and stress was high (Joong Ang sunday, 2015). According to recent Australian job satisfaction survey, workers in remote areas far from large cities showed a $10 \%$ higher satisfaction rate than urban workers, and the highest level of job satisfaction among farmers and fisheries workers, while workers in customer service sector such as hotel has the lowest in the sense of happiness for their work (The Sydney Korean Herald, 2017).

Therefore, it is very important for the worker that when they look at natural landscape rather than urban landscape, their sense of happiness are improved (Van den Berg et al., 2003). If installation of the indoor garden using the indoor plants enhances effectively the interest in the available plants or if the sensitivity and the psychological state of the workers to the plants are sufficiently reflected, the effect can be far greater. It is necessary to clarify and analyze the preference of workers for indoor plants or indoor gardening at work places as well as psychological conditions including their awareness of psychological healing effects, and emotional images.

This study was carried out in order to create a healthier indoor environment and to spread related industry by reconsidering the perception of functions and effects on the experience of workers installing indoor garden. The purpose of this study was to investigate the effect of indoor gardening experience of workers staying in indoor space for a long time during the day.

\section{Study Method}

\section{General Characteristics of Participants}

In order to investigate the changes in psychological healing according to the experience of the indoor gardening of the workers, we conducted survey on the participants in December (Fig. 1) before experiencing the indoor gardening set up in the space of each floor at the National Institute of Horticultural and Herbal Science (Figure 1), carried out installation experience two months later and conducted survey on workers who had experience in indoor gardening three months after the installation (in May). Later, analysis on survey was conducted on 55 questionnaires out of 62 respondents with exclusion of seven inappropriate and retired workers. Most of them participated in indoor gardening except for some workers with no particular reason.

\section{Items on Questionnaire}

Items on the questionnaire are made up of changes in perceived change (changes in the interest of the gardening element) of the indoor garden before and after the indoor gardening experiment, psychological change (attention restoration scale, semantic differential method, sense of loyalty, color preference) and general items to find out changes of participants before and after experiencing indoor gardening. 


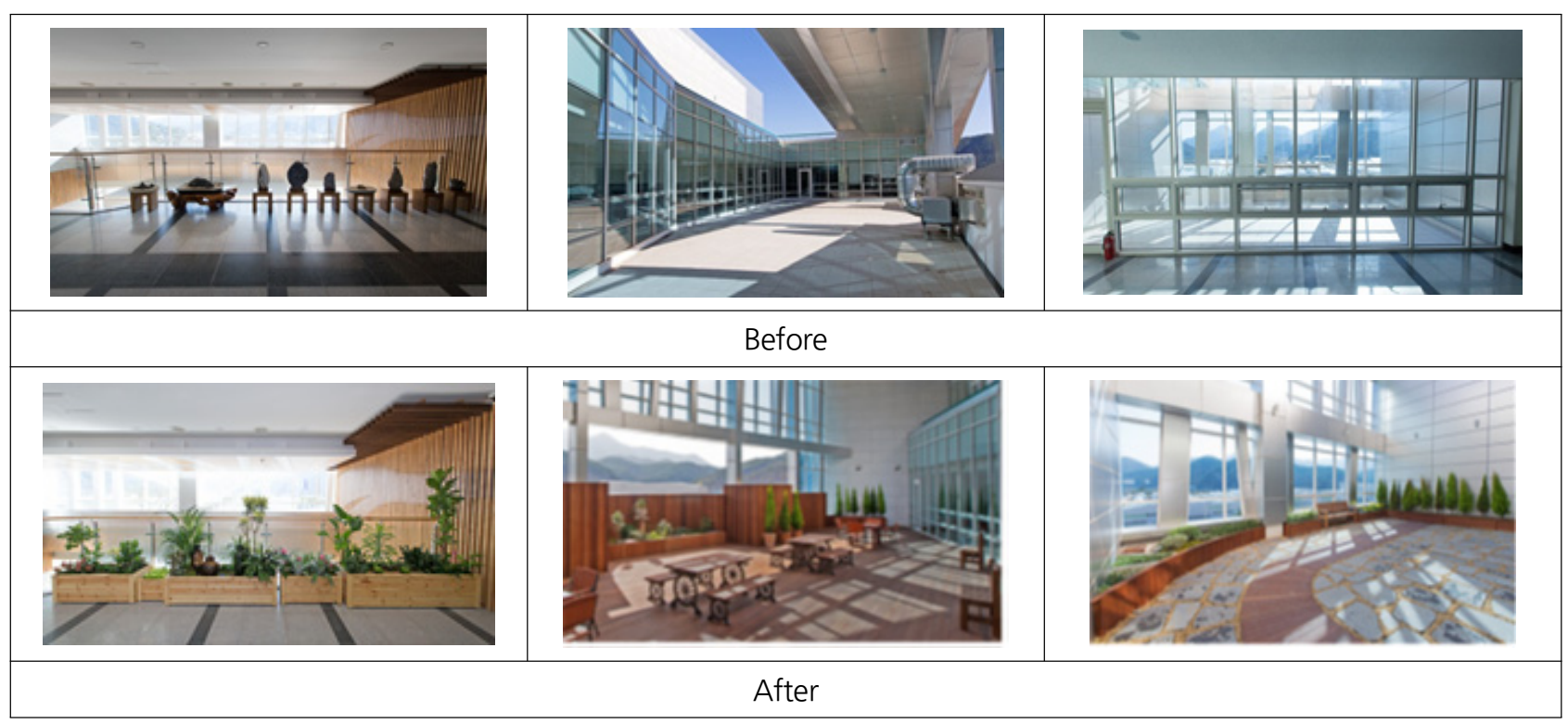

Figure 1. Before and after the establishment of indoor garden at the lobby of National Institute of Horticultural \& Herbal Science.

\section{Psychological healing effect of indoor garden installation}

The psychological healing effect of the indoor garden was measured by the forest healing effectiveness scale used by Kim (2012), adjusted to the indoor garden. In addition, each question was to be answered in a four-point of Likert scale at the same time the extremely not was rated 1 point, the extremely so rated 4, and Cronbach's $\alpha$ value was 0.908 .

\section{Attention restoration scale}

In this study, we used the 7-point of Likert scale (negative to positive) for the 7 items of attention restoration scale of Lee (2011), which was adapted from the items of Staats et al. (2003) (Table 1). In this study, the value of Cronbach's $\alpha$ was 0.903 .

\section{Semantic differential method: SD method}

Semantic differential method is widely used for the evaluation of landscape, which changes in value according to

Table 1. Workers attention restoration scale following after indoor garden installation on the indoor plants and gardens.

\begin{tabular}{ll}
\hline No. & \multicolumn{1}{c}{ Item $^{\mathrm{z}}$} \\
\hline A & It seems to be clam down in here. \\
B & It seems to recover the energy in here. \\
C & It seems to re-discover myself in here. \\
D & It seems to be relax in here. \\
E & It seems to be re-organizing the thoughts in here. \\
F & It seems to disremember everything in here. \\
G & It seems to recover the concentration in here. \\
\hline
\end{tabular}

${ }^{\mathrm{z}}$ Attention restoration scale: 7 :extremely so $\sim 1$ : extremely not. 
individual subjective style and preference and is difficult to quantify. It was developed by Osgood et al. (1957) as a method for evaluating imagery space of humans, and is widely used in landscape or emotional evaluation. In this study, among emotional adjectives for landscape evaluation (Im, 2009) and emotional adjectives which can be related to plants, three pair of them are used - 'unpleasant - pleasant', 'artificial - natural' and 'exciting - calming' to evaluate emotional state. Semantic differential method presents 7-point of Likert scale (very unstable: -3, very calm: 3 ) and allows respondents to respond according to the degree of which respondents feel closer to (Jang et al., 2014; Kim, 2012; Park, 2010).

\section{Loyalty to plants}

Loyalty is defined as the degree of affection (Aaker, 1992), which indicates the degree of customer's continued attachment to a particular brand, as well as repurchase intention and behavior of a certain product (Lee, 2003). Loyalty is defined as the consumers' commitment with consumers' desire of repurchase, which can be divided into emotional loyalty, cognitive loyalty, and behavioral loyalty (Oliver, 1999). Therefore, if such emotions or cognitive loyalty through indoor gardening experiences are satisfied with the experience of indoor gardening, customers greatly tend to repurchase and recommend to surrounding people they know (Zeithaml et al., 1996). The customer loyalty scale used in this study (Table 2) was re-adjusted from the one used by Gremler (1995) according to the situation, with five items ranging from A to $\mathrm{E}$ in loyalty, and each items should be answered with five points of Likert scale (1: negative to 5: positive) (Zeisel, 1981), and the Cronbach's $\alpha$ value of this study was 0.924 .

\section{Color preference of foliage plants and flowers during indoor gardening}

In order to find the color preference of foliage plants or flowers during facilitating indoor garden, eight colors (white, red, pink, yellow, orange, green, purple, and blue) of flowers and foliage plants photographed were suggested and the respondents were supposed to answer their color preference of foliage plants or flowers during indoor garden installation on the basis of five points (1: negative $\sim 5$ :positive) of Likert scale.

\section{Statistical analysis}

The collected data was analyzed by using IBM SPSS ver. 20.0. The reliability analysis of this measurement tool calculated Cronbach's $\alpha$. Paired t-test was used for the psychological healing effect of indoor garden, attention restoration scale, semantic differential method and loyalty. Color preference for plant was analyzed by One-way ANOVA while frequency analysis was performed for general items.

Table 2. User's loyalty of indoor plants and gardens.

\begin{tabular}{cl}
\hline $\mathrm{L}^{\mathrm{z}}$ & \multicolumn{1}{c}{ Item } \\
\hline A & Be able to talk positively to other people regarding to grow indoor plant \\
B & Intend to invest more fund to purchase indoor plant. \\
C & Strongly recommend to purchase indoor plant to relatives or friends. \\
D & It was the best choice to purchase the indoor plant. \\
E & I would like to move into an office with superior indoor landscaping. \\
\hline
\end{tabular}

${ }^{\mathrm{z}}$ Loyalty: $5=$ extremely so, $4=$ so, $3=$ normal, $2=$ not so, $1=$ extremely not. 


\section{Result and Consideration}

\section{General Characteristics}

Out of the total respondents, $54.4 \%$ were for males and $45.6 \%$ were for females, relatively higher among male respondents. Experts were $22.8 \%$ and $77.2 \%$ are not experts while $29.8 \%$ are fifties, $28.1 \%$ in $40 \mathrm{~s}, 26.3 \%$ in $30 \mathrm{~s}, 8.8 \%$ in $60 \mathrm{~s}$ and higher, and $7.0 \%$ in their $20 \mathrm{~s} .35 .1 \%$ are graduated from graduate school (or being in graduate school), college graduates or undergraduates (31.6\%), high school graduates (19.3\%) and others 14\% (data not shown).

\section{Changes in general perception according to indoor gardening experience}

\section{Changes in interest according to experience of indoor gardening}

The results of this study are as follows: before experiencing indoor garden installation, more than $50 \%$ of respondents said it would be difficult to install indoor garden. However, experiencing installation, the sense of burden against management decreased to $35 \%$, drop by $15 \%$, and respondents showed a tendency to increase interest in kinds of plants and landscape design (Fig. 2). This result was similar to the one that the landscape design was most important in the analysis of human psychological effect on green interior for residental space (Yoo et al., 2015). The results of the study on the changes of kinds of plants the workers want to plant before and after indoor garden installation were as follows (Fig. 3). After experiencing, preference for flowering plants and succulent plants was lowered, and preferences of green foliage plants and herb plants were $10 \%$ higher. As a result of examining how much investment can be personally made for indoor garden installation, the respondents with the cost of less than 500,000 won increased by $6 \%$ less after the experience while those with 500,000 won to 1.99 million won in investment changed their mind to more than 4 million won after the experience (Fig. 4). In addition, as a result of analyzing perception changes toward psychological healing effects from indoor garden, the average score of the psychological healing effects all increased in five items after the experience (Table 3). In particular, the item of "the garden increases the air purification effect" shows higher score which is statistically significant. As a result of this study, though it has no significant statistical importance, the fact that the perceived level of "psychological stabilization effect" on indoor garden was higher, has similar tendency with the report by Jang et al., (2016), which showed that there are high scores in items such as "indoor garden enhances psychological stabilization effect"and "indoor garden improves air purifying effect" in the study on psychological effects of indoor garden within resting place of public buildings. Accordingly, it is thought that the air cleaning, the stressful feeling or psychological anxiety against fine dust, which have recently emerged as big problems, have a great influence on the recognition of the positive effect of the indoor garden.

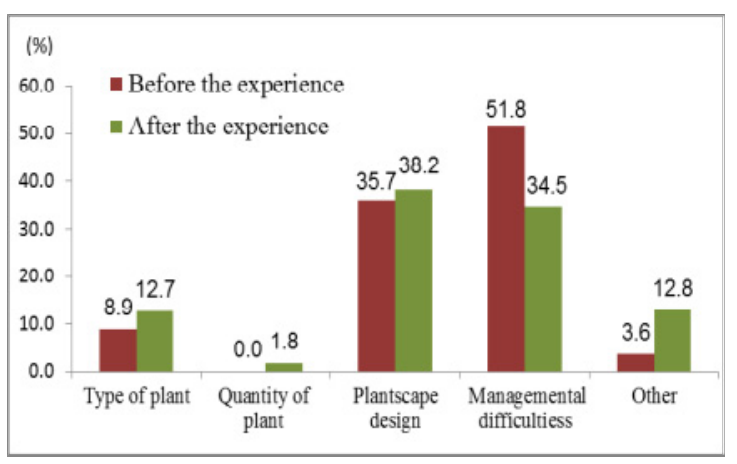

Figure 2. Change in concern element before and after the experience indoor garden installation.

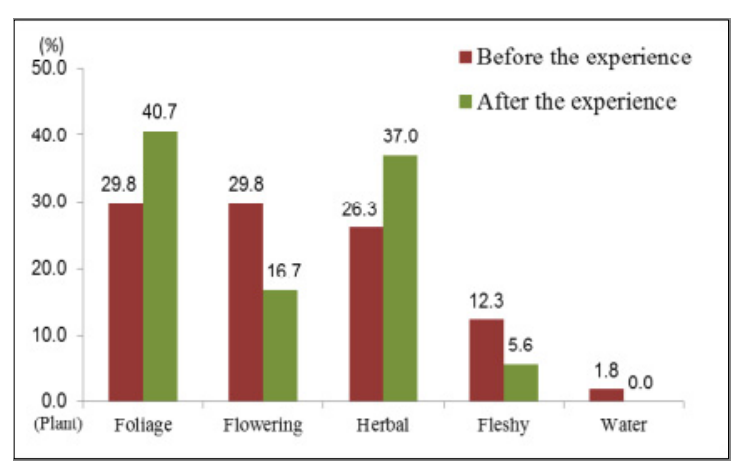

Figure 3. Change in preference of plant before and after the experience indoor garden installation. 


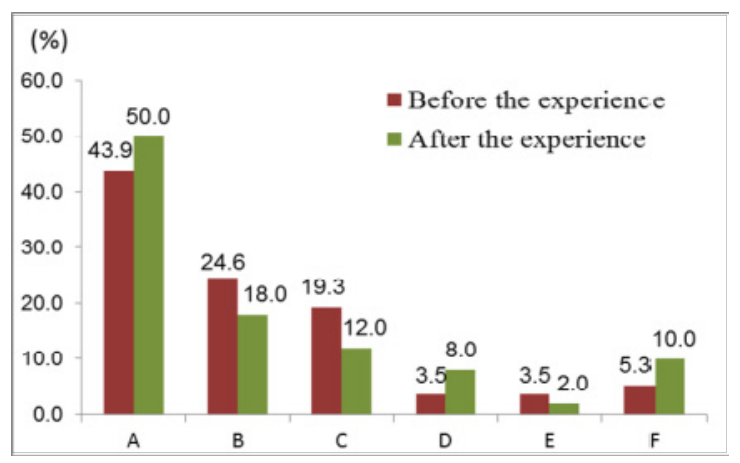

Figure 4. The investment money for the indoor garden installation. A: Under 500,000won, B: 500,000 - 990,000won, C: 1,000,000 - 1,990,000won, D: 2,000,000 - 2,990,000won, E: 3,000,000 - 3,990,000won, F: Over 4,000,000 won.

Table 3. Response of psychological effect of indoor garden before and after the experience indoor garden installation.

\begin{tabular}{lccccc}
\hline \multicolumn{1}{c}{ Treatment } & A1 & A2 & A3 & A4 & A5 \\
\hline Before the experience & $2.962 \pm 0.66^{\mathrm{y}}$ & $2.490 \pm 0.76$ & $2.760 \pm 0.87$ & $3.132 \pm 0.76$ & $2.784 \pm 0.81$ \\
After the experience & $3.135 \pm 0.56$ & $2.667 \pm 0.82$ & $2.960 \pm 0.67$ & $3.189 \pm 0.53$ & $2.902 \pm 0.67$ \\
\hdashline$t$-value & -2.021 & -1.419 & -1.696 & -0.553 & -1.098 \\
\hdashline$p$-value & $0.049^{*}$ & $0.162^{\mathrm{NS}}$ & $0.096^{\mathrm{NS}}$ & $0.582^{\mathrm{NS}}$ & $0.278^{\mathrm{NS}}$ \\
\hline
\end{tabular}

Values are Mean \pm standard deviation $(n=55)$.

A1=Indoor garden improves effect of air cleaning; A2=Indoor garden can cure an atopic dermatitis; A3=Indoor garden can improve the efficiency of worker; A4=Indoor garden improves psychological stability; A5=Indoor garden improves a spontaneous cure.

${ }^{*} p<.05$, respectively; ${ }^{\mathrm{NS}}$ Non-significant.

Table 4. Change of attention restoration scale after the experience indoor garden installation.

\begin{tabular}{|c|c|c|c|c|c|c|c|}
\hline Treatment & A & $\mathrm{B}$ & $\mathrm{C}$ & $\mathrm{D}$ & $\mathrm{E}$ & $\mathrm{F}$ & G \\
\hline Before the experience & $4.715 \pm 1.56$ & $3.982 \pm 1.72$ & $3.807 \pm 1.88$ & $4.035 \pm 1.78$ & $4.281 \pm 1.63$ & $3.860 \pm 1.75$ & $4.193 \pm 1.78$ \\
\hline After the experience & $4.964 \pm 1.45$ & $4.754 \pm 1.34$ & $4.561 \pm 1.63$ & $4.877 \pm 1.56$ & $4.965 \pm 1.48$ & $4.263 \pm 1.66$ & $4.632 \pm 1.58$ \\
\hline$t$-value & -2.769 & -2.674 & -2.671 & -3.074 & -2.570 & -1.437 & -1.445 \\
\hline$p$-value & $0.008^{* *}$ & $0.01^{* *}$ & $0.01^{* *}$ & $0.003^{* *}$ & $0.013^{*}$ & $0.156^{\mathrm{NS}}$ & $0.154^{\mathrm{NS}}$ \\
\hline
\end{tabular}

Values are Mean \pm standard deviation $(n=55)$

$\mathrm{A}=$ 'It seems to be clam down in here'; $\mathrm{B}=$ ='It seems to recover the energy in here'; $\mathrm{C}=$ 'It seems to re-discover myself in here'; $\mathrm{D}=$ 'It seems to be relax in here'; $\mathrm{E}=$ 'It seems to be re-organizing the thoughts in here'; $\mathrm{F}=$ 'It seems to disremember every thing in here'; $\mathrm{G}=$ 'It seems to recover the concentration in here'.

${ }^{*},{ }^{* *}$ significant at $p<.05, .01$ by paired t-test; ${ }^{\text {NS }}$ Non-significant.

\section{Changes in Psychological Healing of Workers Before and After Experiencing Indoor Gardening}

\section{Attention restoration scale}

As a result of studying attention restoration index of participants before and after indoor garden installation with five points of Likert scale (Table 4), the index of the five items among the total 7 items were higher in statistically significant way after the experience of indoor gardening $(p<.01)$. It was particularly higher in items of "it seems to be calm down here" (average of 4.715 before, average of 4.964 after installation) and "it seems to be relax in here" (average 4.035 before 
and average 4.877 after). This results has a very similar tendency with the study result of Herzog et al. (2003) that in attention restoration theory, restoration environment characteristics are better in natural environment than urban environment, and the results of the study by Richardson et al. (2013) that, the natural environment rather than urban one, provides convenience and benefits in psychological restoration experience since in this study the most of restoration index of the workers was higher after indoor garden installation than before, along with far greater changes in psychological stabilization items.

\section{Semantic differential method}

The results of this study were as follows: The sensibility change according to the experience of indoor gardening was evaluated by semantic differential method consisting of three pairs of emotional adjectives (Fig. 5). Refreshing feeling, natural feeling, and soothing feeling were statistically significantly higher after than before experiencing indoor garden installation. ( $p<.001)$. This is similar to the results of Kim (2012), which compared the psychological effects of urban areas, urban forests, and recreational forests, urban forests and recreational forests provide significantly higher emotions of refreshing, natural and soothing than urban areas. In addition, what Jang et al. (2016) studied has a similar tendency with this study that workers felt more of sense of refreshment, sense of nature and soothing feeling after indoor garden installation because the previous study reported that sense of refreshment, naturalness, and sense of calming were higher when the indoor garden was built than when there was no indoor garden in the rest area of public buildings. In addition, it was thought that the workers were able to feel sense of refreshment, sense of naturalness, and calm feeling more through the effect of direct contact with plants and collaboration with co-workers in the process of creating indoor garden.

\section{Changes in the loyalty of worker before and after experiencing indoor gardening}

The results of the Paired t-test (Table 5) were used to examine the changes in the loyalty of the workers before and after experiencing indoor garden installation. The loyalty B (intend to invest ore fund to purchase indoor plant) were statistically significantly higher after experiencing installation. In addition, the remaining four loyalty questions were not statistically significant, but they were higher after experiencing than before, which implies positive results from indoor gardening installation. experience. These results indicate that the outcome of this study is similar to that of Jang et al. (2016) that the amount of investment possible for indoor gardening have impacts on loyalty B (intend to invest more fund to purchase indoor plants). Likewise, the result of the increase in the amount of investment after the experience and "intension to invest more fund to purchase indoor plants"tended to be similar with the degree of loyalty.

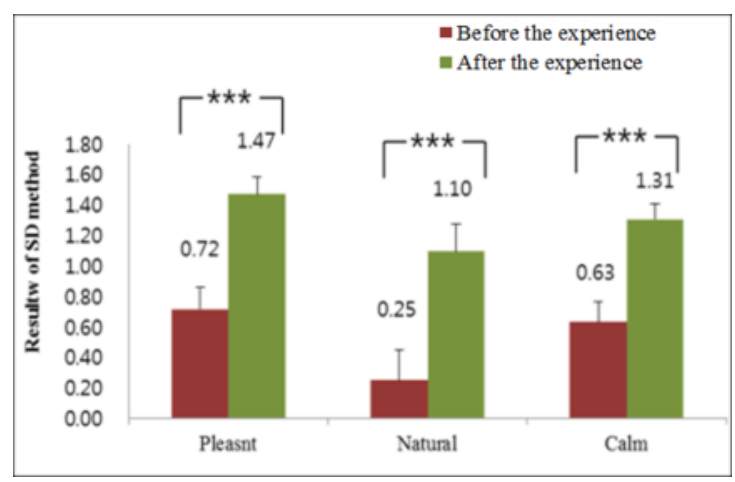

Figure 5. The impact of before and after the experience indoor garden installation to emotional quotient of resident (SD method). ${ }^{* \star *} p<.001$. 
Table 5. Cross comparison for loyalty depending on before and after the existence of indoor garden.

\begin{tabular}{lccccc}
\hline \multicolumn{1}{c}{ Treatment } & $\mathrm{A}$ & $\mathrm{B}$ & $\mathrm{C}$ & $\mathrm{D}$ & $\mathrm{E}$ \\
\hline Before the experience & $3.690 \pm 0.88^{\mathrm{y}}$ & $2.910 \pm 0.10$ & $3.310 \pm 0.93$ & $3.170 \pm 0.95$ & $3.310 \pm 1.10$ \\
After the experience & $3.781 \pm 0.85$ & $3.130 \pm 0.97$ & $3.370 \pm 0.96$ & $3.278 \pm 0.98$ & $3.481 \pm 0.95$ \\
\hdashline$t$-value & -0.868 & -2.059 & -0.434 & -0.747 & -1.102 \\
$p$-value & $0.389^{\mathrm{NS}}$ & $0.044^{*}$ & $0.666^{\mathrm{NS}}$ & $0.458^{\mathrm{NS}}$ & $0.276^{\mathrm{NS}}$ \\
\hline
\end{tabular}

Values are Mean \pm standard deviation $(\mathrm{n}=55)$.

$\mathrm{A}=\mathrm{Be}$ able to talk positively to other people regarding to grow indoor plant; $\mathrm{B}=$ Intend to invest more fund to purchase indoor plant; $\mathrm{C}=$ Strongly recommend to purchase indoor plant to relatives or friends; $\mathrm{D}=\mathrm{It}$ was the best choice to purchase the indoor plant; $\mathrm{E}=\mathrm{I}$ would like to move into an office with superior indoor landscaping.

${ }^{*}$ Significant at $p<.05$, respectively; ${ }^{\text {NS }}$ Non-significant.

\section{Color preference of foliage plants or flowers during indoor garden installation}

In order to evaluate the color preference of foliage plants or flowers in indoor gardening, we showed photographs of eight colors (white, red, pink, yellow, orange, green, purple and blue) and analyzed color preference before and after indoor garden installation. As a result, the $\mathrm{F}$ value was 3.288 and the significance probability was 0.002 , so the color preference for plants or flowers during indoor garden installation was statistically significant (Table 6). Tukey's multirange test showed color preference were in the order of blue, green, yellow, red, purple, orange, pink, and white. In comparison with the report of Jang et al. (2015) that the color preference was in the order of white, green, pink, red, and yellow colors, this study showed the opposite except green color, indicating preferred color can be different according to the characteristics of the space. In addition, similar to the result of comparing the color preference before and after the experiences (Table 7), with similarity to outcomes of comparing the averages, red color was statistically significantly lower after experiencing. Furthermore, although green and blue were not statistically significant, they showed a tendency to increase in preference after experiencing than before. In addition, Li et al. (2012) reported that green and blue usually remind "calm" and "peaceful" will be helpful in stress relieving and health of workers. Lee and Son (1999) also reported

Table 6. Results of Tukey's test in preference of color of indoor garden with plants.

\begin{tabular}{|c|c|c|c|c|c|c|}
\hline & \multirow{2}{*}{ Color } & \multirow{2}{*}{$\mathrm{N}$} & \multirow{2}{*}{ Mean } & \multirow{2}{*}{ SD } & \multicolumn{2}{|c|}{ Tukey's test $\mathrm{a}=0.05$} \\
\hline & & & & & 1 & 2 \\
\hline \multirow{8}{*}{ Preference } & White & 55 & 3.20 & 0.75 & $a^{z}$ & \\
\hline & Pink & 54 & 3.20 & 0.75 & $\mathrm{a}$ & \\
\hline & Orange & 52 & 3.42 & 0.78 & $\mathrm{a}$ & $\mathrm{b}$ \\
\hline & Purple & 55 & 3.51 & 0.89 & $\mathrm{a}$ & $\mathrm{b}$ \\
\hline & Red & 55 & 3.55 & 0.81 & $\mathrm{a}$ & $\mathrm{b}$ \\
\hline & Yellow & 55 & 3.56 & 0.78 & $\mathrm{a}$ & $\mathrm{b}$ \\
\hline & Green & 55 & 3.78 & 0.93 & & $\mathrm{~b}$ \\
\hline & Blue & 55 & 3.72 & 0.74 & & \\
\hline \multicolumn{4}{|c|}{$F$-value } & 3.288 & & \\
\hline \multicolumn{4}{|c|}{$P$-value } & 0.002 & & \\
\hline
\end{tabular}

${ }^{z}$ Mean separation within columns by Tukey's multiple range test, $5 \%$ level $(n=55)$. 
Table 7. Cross comparison for color depending on before and after the existence of indoor garden.

\begin{tabular}{lcccccccc}
\hline \multicolumn{1}{c}{ Preference } & White & Red & Pink & Yellow & Orange & Green & Purple & Blue \\
\hline Before the experience & $3.23 \pm 0.98$ & $3.67 \pm 1.09$ & $3.12 \pm 1.04$ & $3.60 \pm 0.93$ & $3.44 \pm 1.02$ & $3.56 \pm 1.09$ & $3.62 \pm 1.00$ & $3.67 \pm 1.00$ \\
After the experience & $3.12 \pm 0.75$ & $3.38 \pm 0.74$ & $3.20 \pm 0.70$ & $3.40 \pm 0.84$ & $3.31 \pm 0.82$ & $3.69 \pm 0.85$ & $3.36 \pm 0.92$ & $3.81 \pm 0.84$ \\
$n$ & 0.846 & 2.174 & -0.562 & 1.300 & 0.846 & -0.756 & 1.631 & -0.785 \\
-value & $0.401^{\mathrm{NS}}$ & $0.034^{*}$ & $0.577^{\mathrm{NS}}$ & $0.200^{\mathrm{NS}}$ & $0.402^{\mathrm{NS}}$ & $0.453^{\mathrm{NS}}$ & $0.109^{\mathrm{NS}}$ & $0.436^{\mathrm{NS}}$ \\
\hline$p$-value & & & & & & &
\end{tabular}

Values are Mean \pm standard deviation $(\mathrm{n}=55)$.

"Significant at $p<.05$ respectively; ${ }^{\text {NS }}$ Non-significant.

that indoor garden with green foliage plants gives a sense of calming while watching the green plants and Wells (1997) and Kim (1997) showed that the color is most effective in helping observers enjoy mental stability and flexibility as well as blue and green have highest preference similar to our results.

\section{Conclusions}

This study was conducted to investigate the changes of psychological healing according to the experience of indoor garden installation, in which out of the total of 62 workers with exception of 7 who left the company or turned out to be inappropriate, we conducted survey on 55 before and three months after indoor garden installation done through workers' collaboration. It was found that more than $50 \%$ of the respondents thought that the management of the indoor garden would be difficult before the experiment. However, the burden of management after the experience of the composition decreased and the interest in the kinds of plants and landscape design tended to increase. The psychological effect of the workers on the indoor garden was significantly higher in item of "indoor garden increases impact of air cleaning"after experiencing indoor garden installation. As a result of comparing two psychological indicators, the attention restoration index of the workers according to experience of indoor gardening was significantly higher after experiencing than before $(p<.05)$. As a result of emotional evaluation for the sense of refreshment, natural feeling, and soothing feeling by using the attention differential method, workers felt more of them after indoor gardening experience. In addition, the loyalty was statistically significantly higher in the question "tend to invest more fund to purchase plants" after experiencing $(p<.05)$. This result is similar to the results of Jang et al. (2016) that the resident's restoration index, pleasant feeling, and calm feeling were higher with the presence of indoor garden within the rest place of public buildings than when there was no indoor garden in terms of the psychological effect. Therefore, in this study of analyzing the psychological healing changes, there were perception changes on indoor garden through experiencing indoor garden installation in the workplace and the view of the indoor garden created by themselves. Also, as the psychological healing effect on the indoor garden increases, it is judged that the emotional health promotion and the increase of investment could have positive impact on spreading of the indoor garden.

\section{References}

Aaker, D.A. 1992. Managing brand equity: Capitalizing on the value of a brand name. J. Mark. 56(2):125-128. DOI: $10.2307 / 1252048$

Astin, J.A., S.L. Shapiro, D.M, Eisenberg, and K.L. Forys. 2003. Mind-body medicine: State of the science, implications for practice. J. Am. Board Fam. Pract. 16(2):131-147. DOI: 10.3122/jabfm.16.2.131 
Choi, K.M., W.S. Shin, P.S. Yeoun, and Y.M. Cho. 2011. The influence of forest walking exercise on human, stress and fatigue. J. Korean Inst. For. Recreat. 15(1):61-66.

Gremler, D.D. 1995. The effect of satisfaction, switching costs, and interpersonal bonds on service loyalty. PhD Diss., Arizona State Univ., Arizona, USA.

Herzog, T.R., C.P. Maguire, and M.B. Nebel. 2003. Assessing the restorative components of environments. J. Environ. Psychol. 23(2):159-170. DOI: 10.1016/S0272-4944(02)00113-5

Im, S.B. 2009. Theories in landscape analysis. Revised ed. Seoul Natl. Univ., Press, Seoul, Korea.

Jang, H.S., E.H. Yoo, K.J. Kim, and H.H. Jung, 2015. Preference and image perception for color and shape in green interior. J. Korean Soc. People Plants Environ. 18(5):413-420. DOI: 10.11628/ksppe.2015.18.5.413

Jang, H.S., K.J. Kim, E.H. Yoo, and H.H. Jung. 2016. Impact of indoor-garden in the public building of lounge to the psychological effect of resident. J. Korean Soc. People Plants Environ. 19(3):167-174. DOI: 10.11628/ksppe.2016.19.3.167

Jang, H.S., K.J. Kim, H.H. Jung, M. Khalekuzzaman, and E.H. Yoo. 2014. Effect of green interior office on emotional psychology of human. J. Korean Soc. People Plants Environ. 17(6):555-560. DOI: 10.11628/ksppe.2014.17.6.555

Joong Ang SUNDAY. 2015, November 22. Can’t expect...you get cancer due to the stress from work-force. Retrieved from http://sunday.joins.com

Kim, B.K. 1997. Study regarding visual preference anger analysis of an indoor landscape architecture plant. PhD. Diss., Kyunghee Univ., Suwon, Korea.

Kim, K.M. 2012. Study on the effects of forest healing according to types of recreational forests. PhD. Diss., Chungbuk Natl. Univ., Cheongju, Korea.

Lee, J.S. and K.C. Son. 1999. Effects of indoor plant and various colors stimuli on the changes of brain activity and emotional responses. J. Korean Soc. Hort. Sci. 40(6):772-776.

Lee, J.Y. 2003. Effects of air transportation service delay on customer satisfaction, relationship quality, and customer loyalty. PhD. Diss., Gyeongju Univ., Gyeongju, Korea.

Lee, S.H. 2011. The comparisons of urban, green roof, and forest scenes by rating psychological indices. Seoul Stud. 12(3):53-65.

Li, X., Z. Zhang, M. Gu, D-Y. Jiang, J. Wang, Y-M. Lv, Q-X. Zhang, and H-T. Pan. 2012. Effects of plantscape colors on psycho-physiological responses of university students. J. Food, Agri. Environ. 10(1):702-708.

Miyazaki, Y., B.J. Park, and J. Lee. 2011. Nature therapy. In: Osaki, M., A. Braimoh, and K. Nakagami. ed. Designing our future: Perspectives on bioproduction, ecosystems and humanity pp. 407-412. DOI: 10.18356/66aa5f41-en

Oliver, R.L. 1999. Whence Consumer Loyalty?. J. Mark. 3(4):33-44. DOI: 10.2307/1252099

Osgood, C.E., G.J. Suci, and P.H. Tannnenbaum. 1957. The measurement of meaning. Univ. Illinois Press, Urbana, IL, USA.

Park, B.J. 2010. Experimental approach of therapeutic effect of forest recreation activities - focused on viewing and walking in forest environments-. PhD. Diss., Chungnam Natl. Univ., Daejeon, Korea.

Richardson, E.A., J. Pearce, R. Mitchell, and S. Kingham. 2013. Role of physical activity in the relationship between urban green space and health. Public Health 127(4):318-324. DOI: 10.1016/j.puhe.2013.01.004

Staats, H., A. Kieviet, and T. Hartig. 2003. Where to recover from attentional fatigue: An expectancy-value analysis of environmental preference. J. Environ. Psychol. 23(2):147-157. DOI: 10.1016/S0272-4944(02)00112-3

The Sydney Korean Herald. 2017, April 6. The happiness is 3 times more while the small wage. Retrieved from http://koreanherald.com

Ulrich, R.S., R.F. Simons, B.D. Losito, E. Fiorito, M.A. Milis, and M. Zelson. 1991. Stress recovery during exposure to natural and urban environments. J. Environ. Psychol. 11(3):201-230. DOI: 10.1016/S0272-4944(05)80184-7

Van den Berg, A.E., S.L. Koole, and N.Y. Van der Wulp. 2003. Environment preference and restoration: (How) are they related? J. Environ. Psychol. 23(2):135-146. DOI: 10.1016/S0272-4944(02)00111-1 
Wells, S.E. 1997. Horticultural therapy and the older adult population. The Haworth Press, Inc., NY, USA.

Yoo, E., H.S. Jang, K.J. Kim, H.H. Jung, and Y.J. Kim. 2015. Effect of green interior home on emotional psychology of human. J. Korean Soc. People Plants Environ. 18(4):249-256. DOI: 10.11628/ksppe.2015.18.4.249

Yoo, M. 2013. The impact of modulized interior landscape on office workers' psychological wellbeing. PhD. Diss., Seoul Women's Univ., Korea.

Zeisel, J. 1981. Inquiry by design Monterey. Brooks Cole Publishing Co., California, USA.

Zeithaml, V.A., L.L. Berry, and A. Parasuraman. 1996. The behavioral consequences of service quality? J. Mark. 60(2): 31-46. DOI: $10.2307 / 1251929$ 